02

\title{
Влияние свойств водной среды на агрегацию димегина
}

\author{
() И.В. Багров, А.В. Дадеко, В.М. Киселев, Т.Д. Муравьева, А.М. Стародубцев, А.С. Гренишин \\ Государственный оптический институт им. С.И. Вавилова, \\ 199034 Санкт-Петербург, Россия \\ e-mail: kiselevvm21@gmail.com
}

Поступила в редакцию 24.06.2019 г.

В окончательной редакции 24.06.2019 г.

Принято к публикации 08.07.2019 г.

В работе проведено сравнительное исследование влияния свойств водной среды на агрегацию димегина, фотодитазина и радахлорина. Отмечена нелинейная зависимость молярной экстинкции от концентрации фотосенсибилизатора в растворе, причем в различной степени для лекарственной формы раствора и растворов, приготовленных с применением лиофильно высушенных порошков фотосенсибилизаторов. Показано, что применение поверхностно-активных веществ (плюроник F-127 и поливинилпирролидон) в определенных пределах ослабляет проблемы, связанные с агрегацией исследуемых фотосенсибилизаторов.

Ключевые слова: фотосенсибилизатор, синглетный кислород, порфирины, димегин, агрегаты, димеры, спектры поглощения.

DOI: $10.21883 /$ OS.2019.11.48514.221-19

\section{Введение}

Порфириновые фотосенсибилизаторы, как было показано в ряде работ [1-7], имеют заметную тенденцию к агрегации в водных растворах даже в диапазоне низких, микромолярных концентраций, что приводит к изменению фотофизических и фотохимических свойств фотосенсибилизаторов и к заметному понижению их фотокаталитической и фотодинамической активности. Снижение степени агрегации порфиринов и увеличение их фотодинамической активности достигается обычно путем смешивания фотосенсибилизаторов с поверхностноактивными веществами, которые являются достаточно эффективными диспергаторами, предотвращающими в определенной степени процессы агрегации в водных растворах порфиринов [8-14].

Разагрегация раствора порфирина может происходить и при его нагревании [1,15-17]. В частности, для димегина в работе [16] наблюдалось при нагревании повышение концентрации мономеров с одновременным небольшим увеличением и концентрации димеров, что было видно по повышению амплитуды левого крыла спектрального профиля поглощения димегина в пике Соре. Однако эти выводы, как было отмечено в [17], как и перспективы применения поверхностно-активных веществ в качестве диспергаторов нуждаются в дальнейших более детальных исследованиях сложных механизмов агрегационного поведения молекул порфиринов в водных растворах, которые и предполагается сделать в данной работе при сопоставлении свойств димегина с фотодитазином и радахлорином.

\section{Материалы и методика эксперимента}

При проведении исследований в данной работе, как и в работе [17], в качестве фотосенсибилизаторов при приготовлении растворов применялись димегин и фотодитазин в виде лиофильно высушенных порошков, изготовленных в институте биохимии имени А.Н. Баха, РАН, и радахлорин в виде водного $0.35 \%$ раствора для

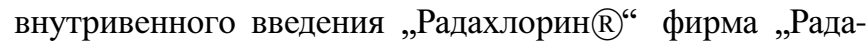
Фарма“, Москва. В качестве растворителя для фотосенсибилизаторов использовалась дистиллированная вода pH 6.0.

При исследовании влияния поверхностно-активных веществ (ПАВ) на разагрегацию растворов фотосенсибилизаторов применялись плюроник F-127 и поливинилпирролидон (ПВП) с молекулярным весом $12600 \mathrm{~g} / \mathrm{mol}$, растворенные в дистиллированной воде. Полученный двухкомпонентный раствор перемешивался на магнитной мешалке при температуре $20-22^{\circ} \mathrm{C}$ в течение $60 \mathrm{~min}$.

При изучении изменения свойств растворов фотосенсибилизаторов при их разбавлении и под воздействием облучения светом оптической накачки применялся спектрофотометрический метод измерения поглощения раствора с использованием спектрофотометра Shimadzu UV-3600. Разбавление растворов фотосенсибилизаторов и фотосенсибилизаторов с ПАВ производилось дистиллированной водой с перемешиванием полученных растворов на магнитной мешалке в течение $10 \mathrm{~min}$ после каждого разбавления. Исходные концентрации димегина, фотодитазина и ПАВ перед разбавлением раствора дистиллированной водой, как правило, были равны $20 \mu \mathrm{M}$.

Источниками оптического возбуждения фотосенсибилизаторов служили светодиодные устройства с длинами волн излучения в диапазоне $\lambda_{m}=400 \mathrm{~nm}$, описание которых приведено в [18]. Люминесценция синглетного кислорода при оптическом возбуждении растворов фотосенсибилизаторов регистрировалась с использованием спектрометра М266. 

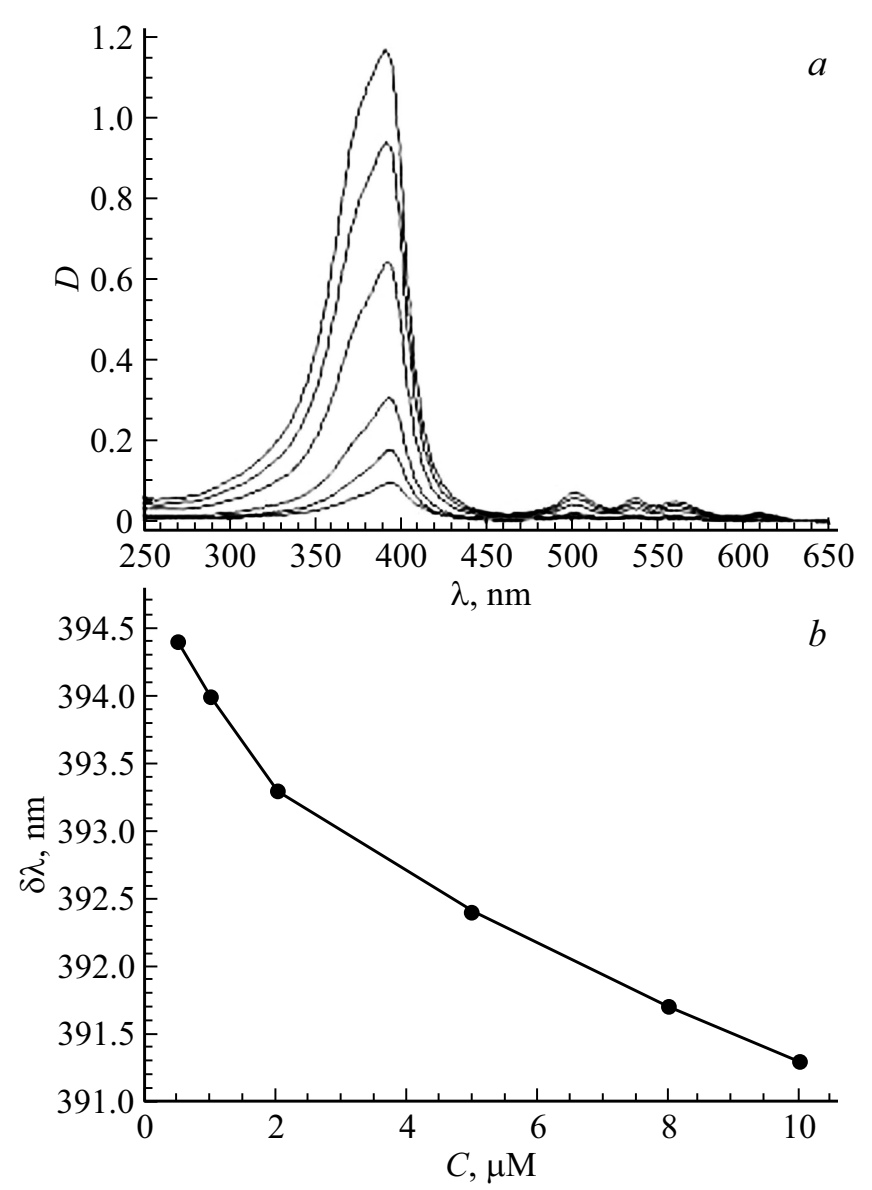

Рис. 1. Спектры поглощения димегина при понижении молярной концентрации раствора $(a): 10,8,5,2,1$, и $0.5 \mu \mathrm{M}$ (сверху вниз) и сдвиг максимума поглощения в пике Соре при этом понижении концентрации $(b)$.

\section{Результаты эксперимента и их обсуждение}

Присутствие в растворе агрегированных форм фотосенсибилизатора, как было отмечено в работах $[7,16]$, отчетливо проявляется в не совсем пропорциональной зависимости оптической плотности раствора от его концентрации при последовательном разбавлении раствора. При этом наблюдается и нелинейная зависимость молярной экстинкции раствора от его концентрации. Наблюдается также и спектральный сдвиг максимума поглощения раствора фотосенсибилизатора в пике Соре. Соответствующие иллюстрации отмеченных закономерностей представлены на рис. 1-3.

На рис. 1 показано изменение спектров поглощения димегина и батохромный сдвиг максимума поглощения в пике Соре при постепенном понижении молярной концентрации путем разбавления раствора димегина дистиллированной водой.

Еще более наглядно батохромный сдвиг максимума поглощения димегина в пике Соре и изменение вида профиля можно наблюдать на рис. 2, на котором для более широкого диапазона изменения молярной концентрации максимумы профилей поглощения приведены к одинаковой амплитуде для удобства их сравнения. Мономеризация раствора при его разбавлении отчетливо прослеживается. Левое крыло спектрального профиля, соответствующее поглощению димеров и других форм

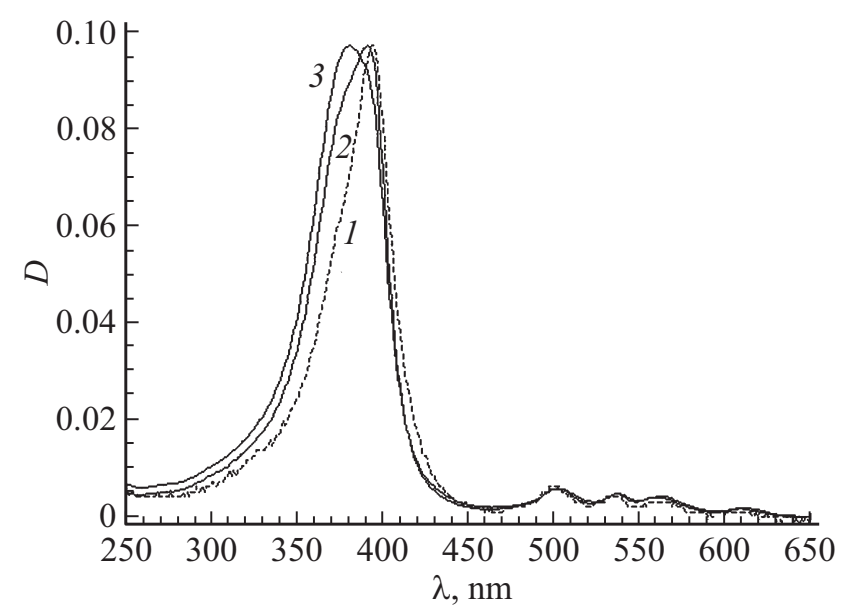

Рис. 2. Спектры поглощения димегина при концентрациях раствора $0.5(1) ; 10$ (2) и $50 \mu \mathrm{M}(3)$.
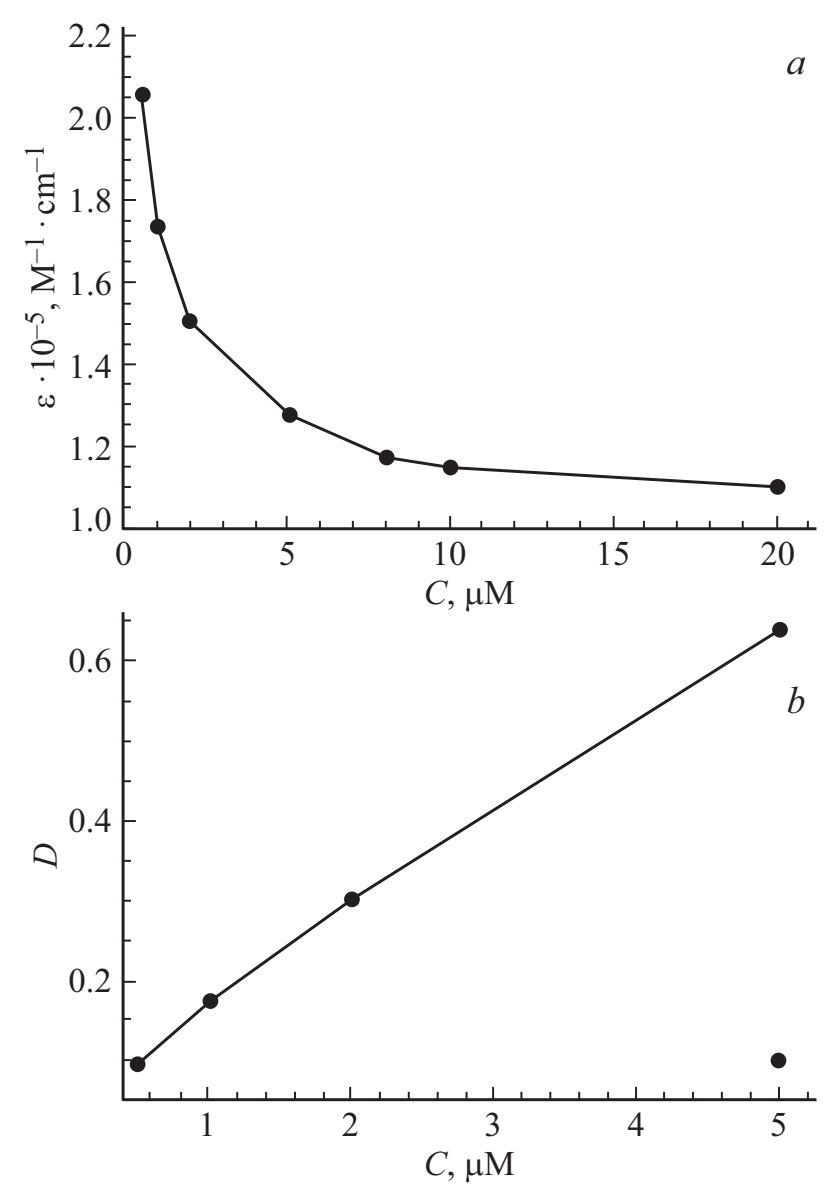

Рис. 3. Зависимость молярной экстинкции $(a)$ и оптической плотности $(b)$ от концентрации димегина. 
агрегатов димегина, заметно уменьшается, а максимум пика Соре смещается к положению, соответствующему поглощению молекулярного раствора.

При понижении концентрации раствора димегина наблюдается и весьма характерный вид зависимости молярной экстинкции раствора, измеренной на длине волны $391 \mathrm{~nm}$, от его концентрации, которая приведена на рис. $3, a$. На рис. $3, b$ показана зависимость оптической плотности раствора димегина от концентрации в растворе для диапазона, где молярная экстинкция наиболее заметно меняется. Нелинейный характер зависимости от концентрации наблюдается и для этой кривой. Похожие нелинейные зависимости от концентрации для молярной экстинкции наблюдались и в работах $[1,7,19]$. Анализируя вид кривой, представленной на рис. $3, b$, можно сделать вывод, что с ростом концентрации раствора димегина в нем наблюдается постепенное усиление эффективности процесса агрегации, который и ограничивает линейный рост оптической плотности раствора.

На рис. 4, $а$ приведены зависимости молярной экстинкции от концентрации для двух форм раствора фотодитазина (лекарственной и свежеприготовленной с применением лиофильно высушенного порошка), измеренные на длине волны $403 \mathrm{~nm}$, в сравнении с кривой для раствора димегина, приготовленного из лиофильно-высушенного препарата. Видно, что раствор фотодитазина, приготовленный с применением лиофильно высушенного порошка, демонстрирует более высокую исходную экстинкцию перед разбавлением раствора по сравнению с димегином при концентрации $20 \mu \mathrm{M}$. При разбавлении растворов наблюдается и заметно меньший прирост экстинкции фотодитазина в диапазоне низких концентраций фотосенсибилизатора, что свидетельствует о меньшей степени агрегации раствора фотодитазина, приготовленного с применением лиофильно высушенного порошка, по сравнению с димегином. Но при этом лекарственная форма раствора, практически совпадающая по величине экстинкции с лиофильной формой на начальном участке разбавления растворов, показывает существенно больший прирост ее в диапазоне низких концентраций фотосенсибилизатора, что свидетельствует о более высокой степени агрегации лекарственной формы раствора.

Объяснение этому различию зависимости молярной экстинкции для двух типов раствора фотодитазина дает рис. $4, b$, на котором представлены спектральные профили поглощения этих двух растворов. Более высокое левое крыло спектрального профиля поглощения лекарственной формы раствора свидетельствует о присутствии в растворе димеров и других форм агрегатов фотодитазина, накапливающиеся в лекарственном растворе в процессе супрамолекулярной самосборки при его длительном хранении, которые при разбавлении раствора дезагрегируются и способствуют более высокому приросту экстинкции.

Самосборка молекул фотосенсибилизатора в агрегатные формы при длительном хранении характерна и для раствора фотодитазина, приготовленного из лиофильно

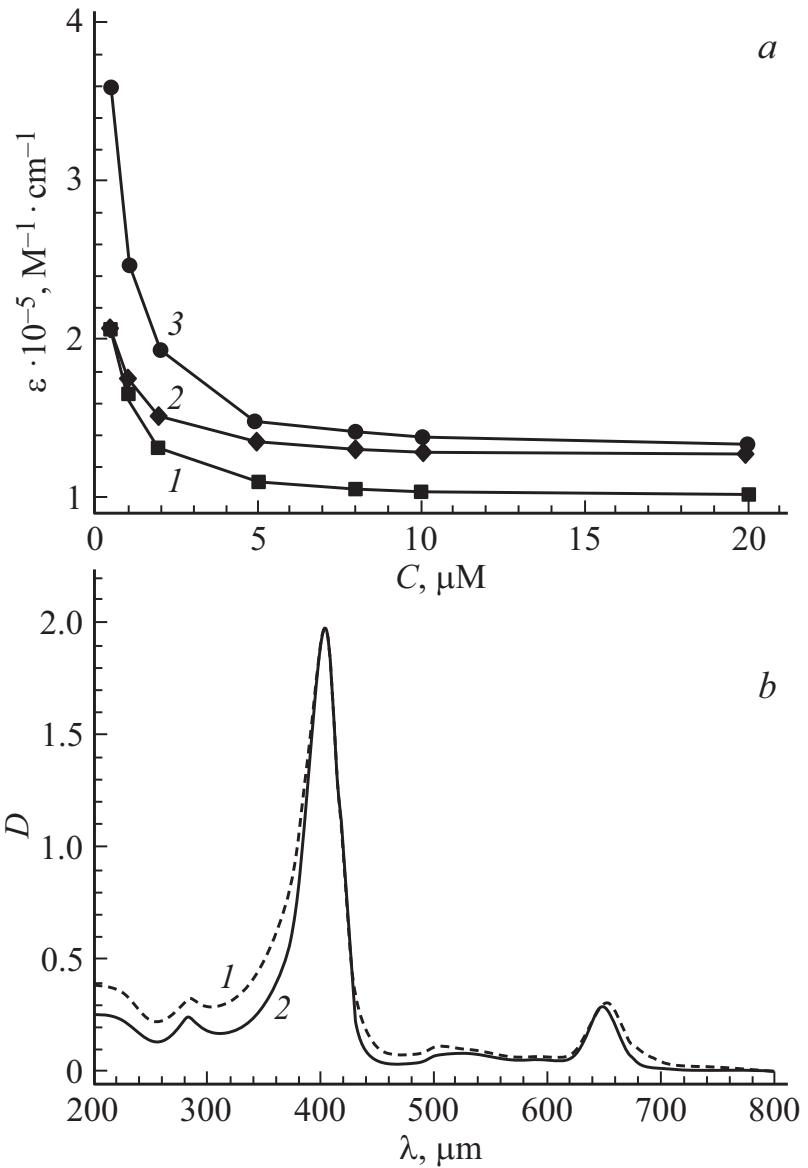

Рис. 4. Зависимость молярной экстинкции димегина (1) и фотодитазина с лиофильной (2) и лекарственной (3) формами растворов от концентрации фотосенсибилизатора $(a)$ и спектры поглощения растворов фотодитазина $(b)$ в лекарственной $(1)$ и лиофильной $(2)$ формах при концентрации $50 \mu \mathrm{M}$.

высушенного порошка. Такой раствор в этом случае подобен длительно хранившейся лекарственной форме. Спектральные профили поглощения свежеприготовленного раствора фотодитазина и раствора после длительного хранения (примерно, 6-8 месяцев) приведены на рис. 5. На рис. 5, $a$ дано реальное соотношение профилей поглощения, а на рис. 5, $b$ максимум в пике Соре раствора после длительного хранения увеличен в 2.2 раза для удобства сравнения спектральных профилей. Подъем крыльев спектрального профиля поглощения раствора после длительного хранения наблюдается и слева, и справа от основного максимума. Следовательно, в растворе происходит образование и Н-агрегатов и J-агрегатов $[19,20]$, хотя с разной степенью интенсивности. Более чем вдвое уширен и максимум поглощения в красной области спектра. Очевидно, что подобные изменения происходят при длительном хранении и в лекарственных формах растворов фотосенсибилизаторов, что и демонстрирует рис. $4, b$.

Для лекарственной формы раствора радахлорина наблюдаются такие же явления, как и для аналогичной 

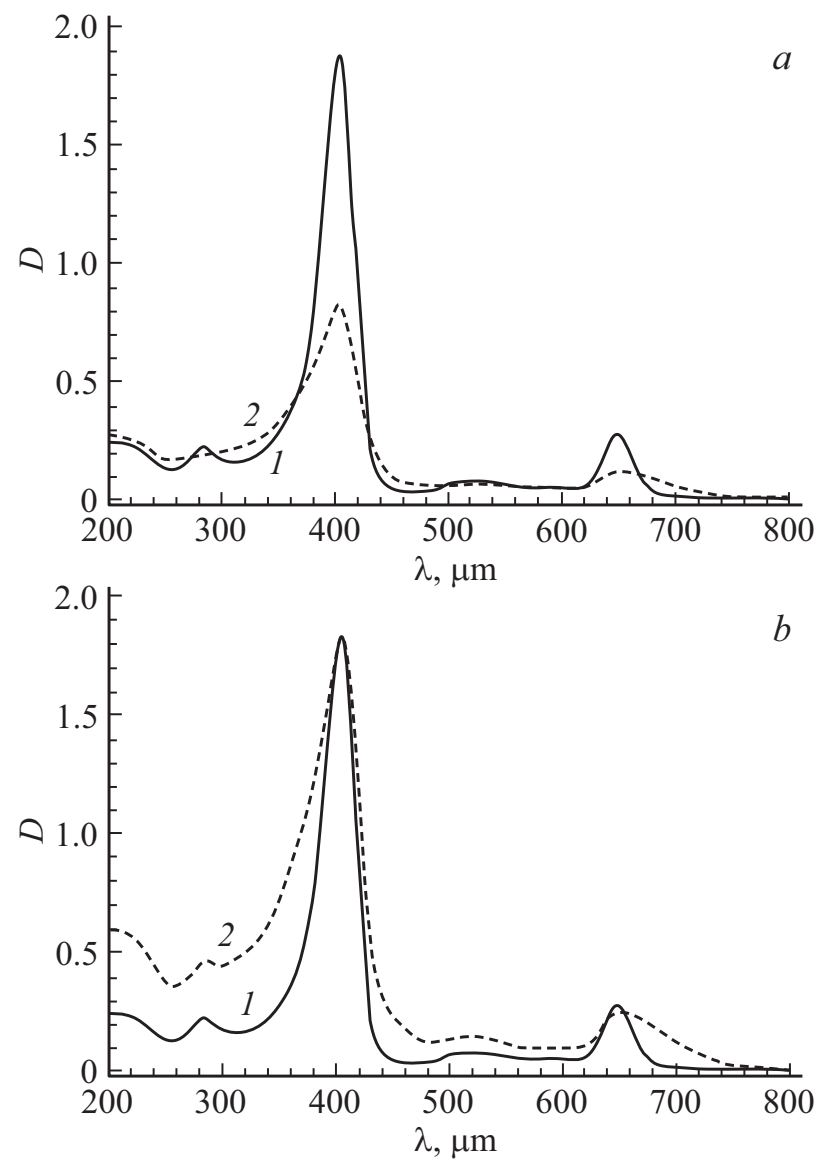

Рис. 5. Спектральные профили поглощения свежеприготовленного раствора фотодитазина (1) и раствора после длительного хранения (2); концентрация растворов $50 \mu \mathrm{M}$.

формы раствора фотодитазина. При характерной для радахлорина меньшей исходной оптической плотности при одинаковых концентрациях растворов по сравнению с фотодитазином и димегином [18] наблюдается и заметно меньшая величина молярной экстинкции в исходном растворе, но прирост ее значения в диапазоне низких концентраций раствора примерно такой же, как и для лекарственной формы фотодитазина. Это ясно видно при сопоставлении рис. $4, a$ и рис. $6, a$.

Отмеченный одинаковый прирост молярной экстинкции для этих двух лекарственных форм коррелирует с практически одинаковым спектральным профилем поглощения этих двух растворов, представленных на рис. 6,6 , с более высоким левым крылом профиля поглощения этих лекарственных форм по сравнению с лиофильным раствором (см. рис. 4, $b$ ). Максимум поглощения в пике Соре радахлорина увеличен в 2.35 раза для удобства сравнения приведенных на рис. $6, b$ спектральных профилей.

При выполнении аналогичного исследования поведения молярной экстинкции при разбавлении исходного раствора для комплекса димегин-плюроник F-127 (poloxamer 407) при соотношении концентраций 1:1 в диапазоне низких концентраций раствора по-прежнему наблюдается нелинейный характер зависимости молярной экстинкции от концентрации (см. рис. $7, a$ ), хотя и с меньшим увеличением молярной экстинкции. При соотношении же концентраций димегина и плюроника $1: 2$ прироста молярной экстинкции при разбавлении раствора уже практически не наблюдается. Хотя начальное значение экстинкции (до начала разбавления раствора дистиллированной водой) с повышением концентрации плюроника заметно увеличивается, что коррелирует с ростом оптической плотности димегина в максимуме пика Соре спектра поглощения растворов, представленных на рис. $7, b$.

Как уже отмечалось ранее [14], добавка плюроника к димегину дает увеличение поглощения в максимуме пика Соре, способствуя дезагрегации раствора за счет мицеллообразования. Поэтому на рис. 7, $a$ исходные значения молярной экстинкции для комплексов находятся несколько выше, чем для раствора собственно димегина. Зависимость солюбилизации или дезагрегации растворов порфиринов от начального соотношения между молярными концентрациями порфирина и

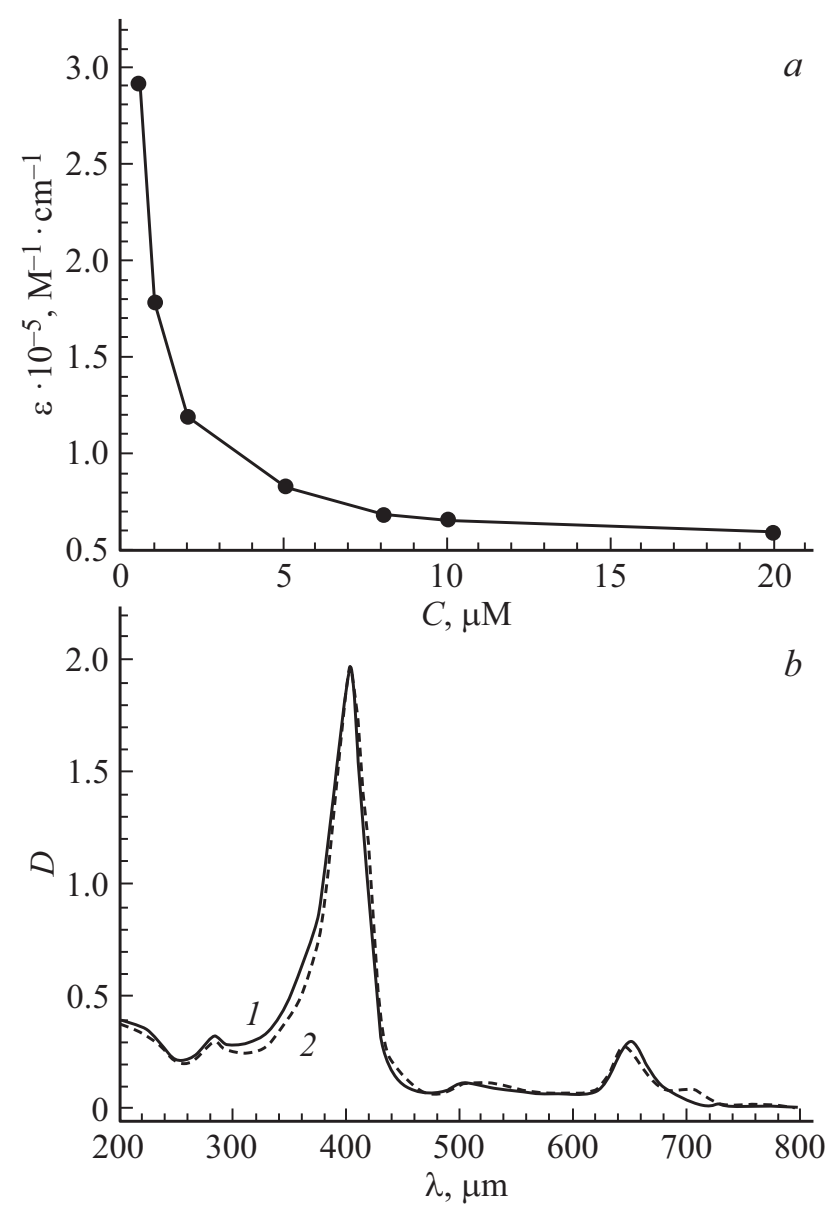

Рис. 6. Зависимость молярной экстинкции радахлорина от концентрации $(a)$ и спектры поглощения $(b)$ лекарственных форм растворов фотодитазина $(1)$ и радахлорина $(2)$; концентрация растворов $50 \mu \mathrm{M}$. 


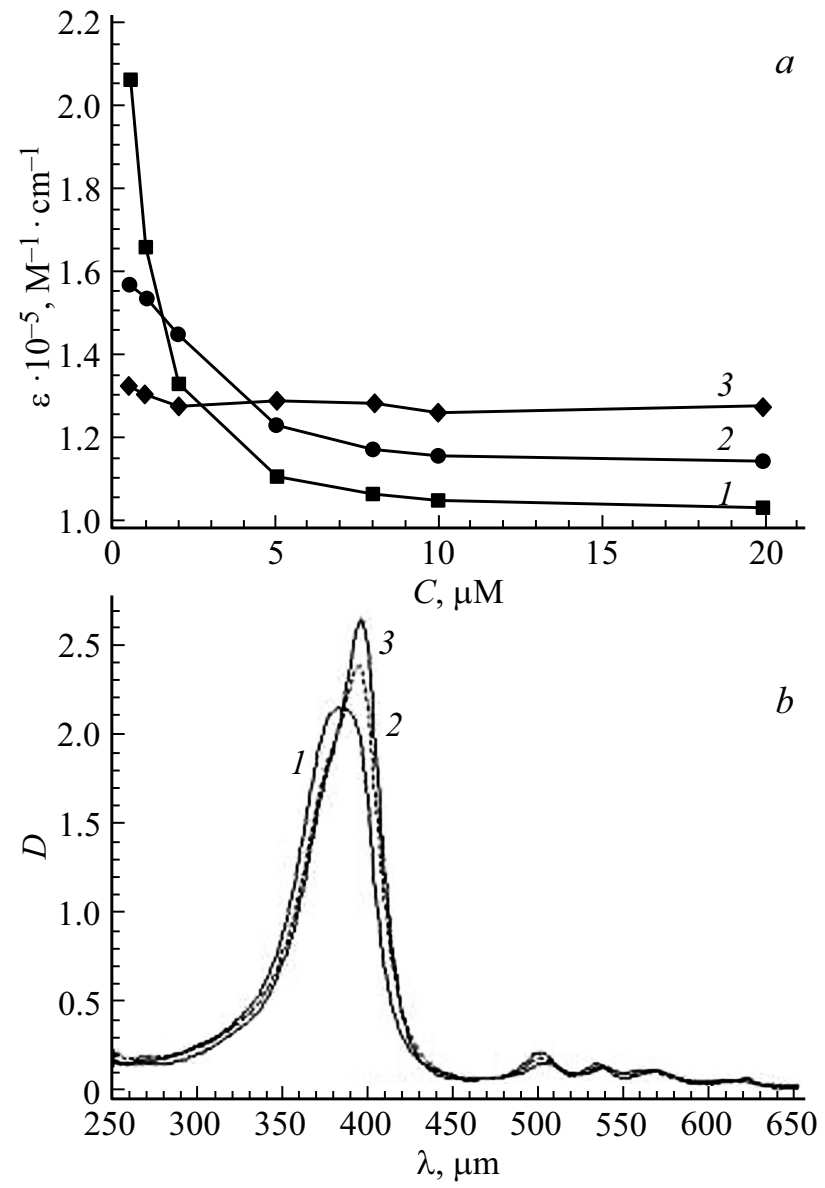

Рис. 7. Зависимость молярной экстинкции димегина (1) и комплекса димегин-плюроник при соотношении концентраций $1: 1(2)$ и $1: 2$ (3) от концентрации раствора $(a)$ и спектры поглощения $(b)$ растворов димегина $(1)$ и комплексов димегинплюроник при соотношении концентраций $1: 1$ (2) и 1:2 (3); концентрация димегина $20 \mu \mathrm{M}$.

плюроника отмечалась и в других работах $[8,9,21]$. Но прирост значения молярной экстинкции в диапазоне низких концентраций раствора при его разбавлении дистиллированной водой, как видно на рис. 7, $a$, для комплексов значительно ниже, чем для раствора димегина. Возможной причиной наблюдаемого результата, по-видимому, может быть известное свойство плюроника, проявляющееся в эффективном образовании комплексов с порфиринами $[22,23]$, в данном случае с димегином в водном растворе плюроника F-127, которые представляют собой достаточно устойчивые структуры и при разбавлении раствора дистиллированной водой препятствуют мономеризации димегина в растворе.

Для сравнения с воздействием плюроника F-127 на дезагрегацию димегина в водном растворе были выполнены аналогичные измерения с влиянием на дезагрегацию димегина поливинилпирролидона (ПВП) с молекулярным весом $12600 \mathrm{~g} / \mathrm{mol}$. Это влияние иллюстрируется на рис. 8, причем на рис. 8, $a$ показано изменение значения молярной экстинкции при разбавлении раствоpa дистиллированной водой, а на рис. $8, b$ приведены спектры поглощения растворов димегина и комплексов димегин-ПВП при соотношении концентраций $1: 1$ и $1: 2$. Ограничение прироста молярной экстинкции комплекса димегин-ПВП, как видно на рис. 8, $a$, выражено в значительно меньшей степени, чем для комплекса димегин-плюроник. Более заметная дезагрегация раствора для комплекса димегин-ПВП наблюдается и на рис. $8, b$ по характерному изменению спектрального профиля поглощения раствора с повышением концентрации ПВП.

На рис. 9, $a$ показано изменение оптической плотности димегина в максимуме пика Соре в водном растворе при увеличении концентрации добавок ПАВ в виде плюроника F-127 и поливинилпирролидона.

Выход на насыщение для обеих кривых объясняется, по-видимому, уже отмеченной выше для плюроника характерной для этих ПАВ склонностью к образованию комплексов с порфиринами $[22,23]$ в водном растворе
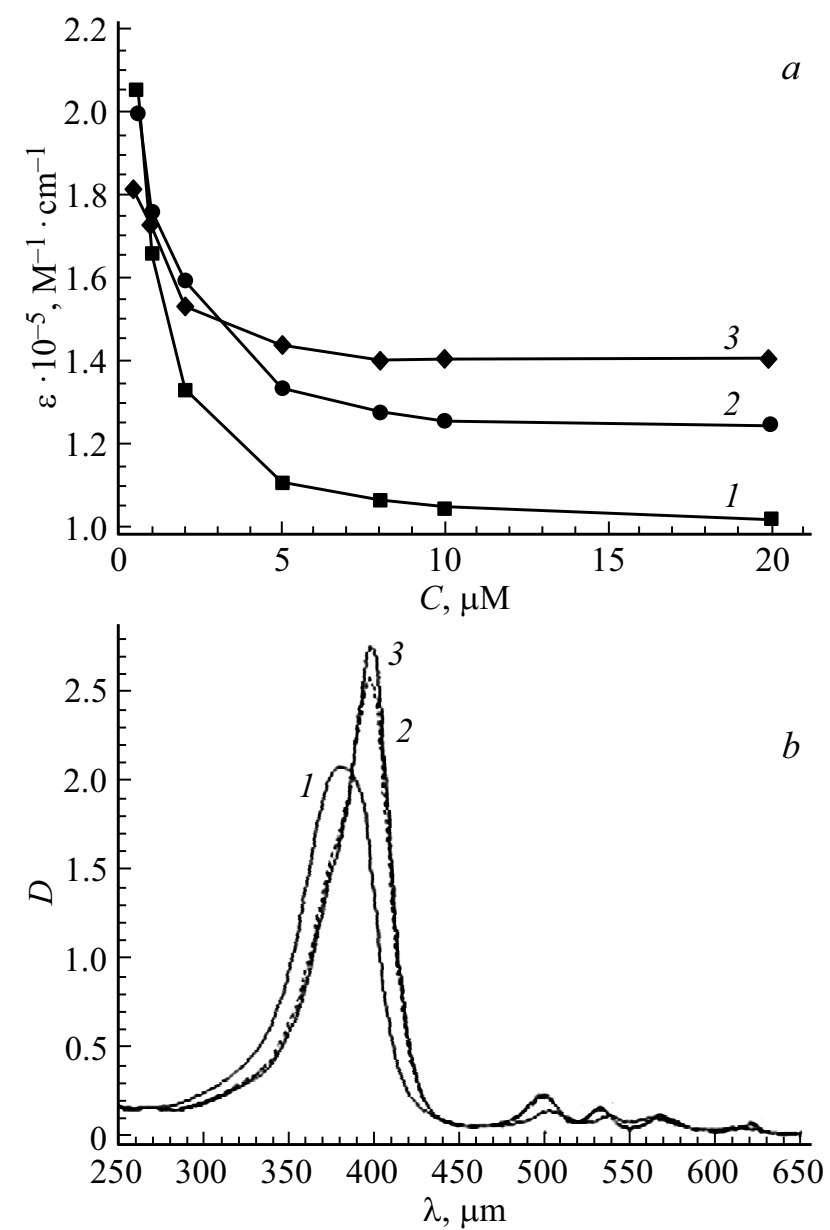

Рис. 8. Зависимость молярной экстинкции димегина и комплекса димегин-ПВП при соотношении концентраций $1: 1$ и $1: 2$ от концентрации раствора $(a)$ и спектры поглощения $(b)$ растворов димегина $(1)$ и комплексов димегин-ПВП при соотношении концентраций $1: 1$ (2) и $1: 2$ (3); концентрация димегина $20 \mu \mathrm{M}$. 

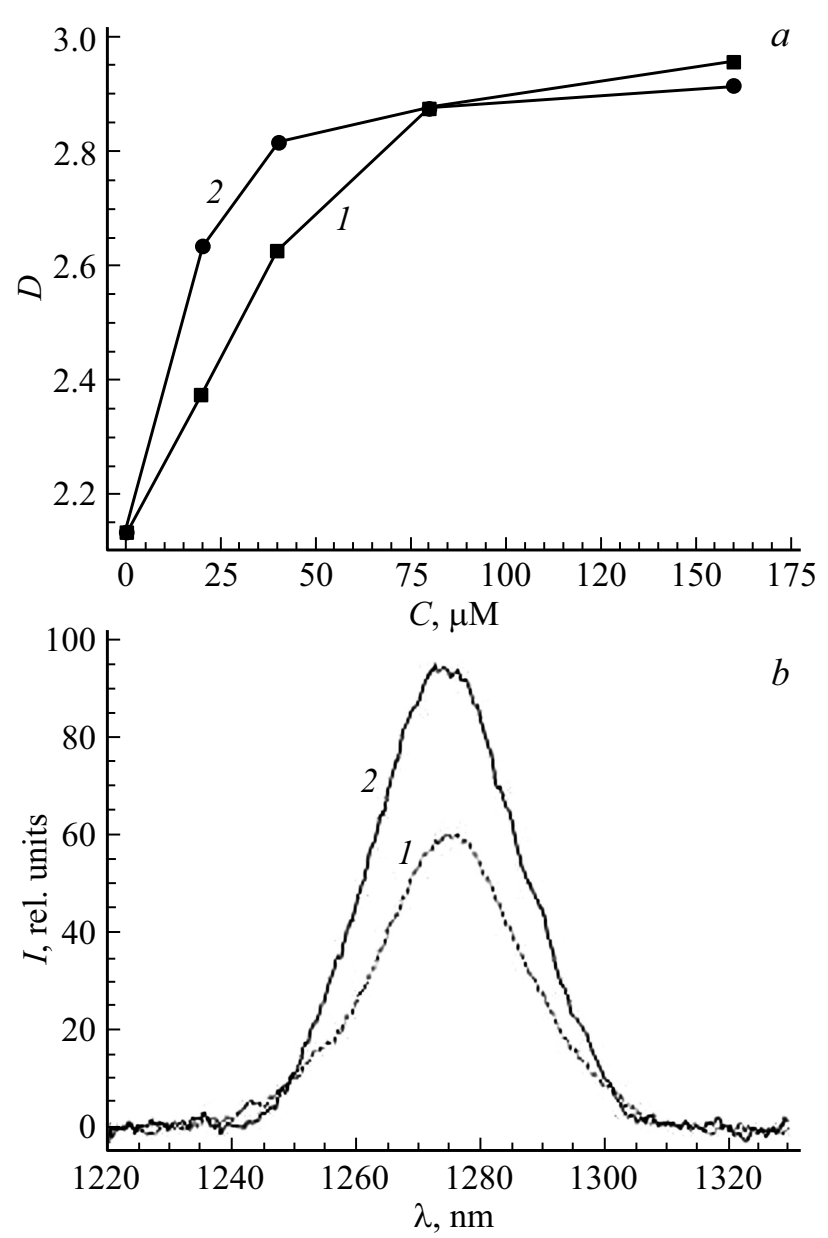

Рис. 9. Зависимость оптической плотности димегина в водном растворе $(a)$ от концентрации плюроника F-127 (1) и поливинилпирролидона (2) и спектральные профили люминесценции синглетного кислорода $(b)$, генерируемого в растворе с плюроником (1) и с ПВП (2) при соотношении концентраций $1: 1$; концентрация димегина $20 \mu \mathrm{M}$.

при повышении их концентрации. Но до выхода на насыщение, как видно на рис. 9, $a$, дезагрегация раствора с применением ПВП происходит более эффективно, чем для плюроника F-127, что можно объяснить меньшей устойчивостью комплексов димегина с ПВП по сравнению с комплексами димегина с плюроником. Более высокая дезагрегация раствора димегина с применением ПВП по сравнению с плюроником отмечалась и в работах [24,25]. Она, в частности, проявляется и в более высокой эффективности генерации синглетного кислорода, иллюстрируемой на рис. 9, $b$.

\section{Заключение}

В результате выполненного исследования влияния свойств водной среды на агрегацию димегина, фотодитазина и радахлорина показано, что свойства агрегации характерны для всех трех исследованных фотосенсибилизаторов. Эти свойства проявляются в нелинейной зависимости молярной экстинкции от концентрации фотосенсибилизатора, наблюдаемой при разбавлении раствора, причем в существенно различной степени для лекарственной формы растворов и свежеприготовленных растворов с применением лиофильно высушенного порошка фотосенсибилизатора. Отмеченное различие объясняется постепенным повышением степени агрегации лекарственной формы раствора при его длительном хранении после акта приготовления.

Поскольку накапливающаяся агрегация раствора при его длительном хранении приводит к заметному понижению фотокаталитической и фотодинамической активности этих фотосенсибилизаторов, то данный фактор необходимо непременно учитывать при практическом применении лекарственных форм растворов фотодитазина и радахлорина.

В работе также показано, что применение поверхностно-активных веществ (плюроник F-127 и поливинилпирролидон с молекулярным весом $12600 \mathrm{~g} / \mathrm{mol}$ ) в определенных пределах заметно ослабляет проблемы, связанные с агрегацией исследуемых фотосенсибилизаторов. Отмеченное ограничение этих пределов по дезагрегации фотосенсибилизаторов в водных растворах с применением плюроника F-127, отчасти, и ПВП, повидимому, связано с возможным влиянием механизма комплексообразования при повышении концентрации добавок поверхностно-активных веществ в раствоpax.

Как итог проведенных исследований следует отметить, что полное понимание рабочих механизмов сложной супрамолекулярной самосборки в виде агрегатов и комплексов фотосенсибилизаторов с ПАВ, проявляющейся в исследуемых растворах, очень важно для создания управляемых систем на базе этих растворов и в данной работе еще не вполне достигнуто, что, повидимому, предполагает проведение более детальных дальнейших исследований этих явлений.

\section{Конфликт интересов}

Авторы заявляют, что у них нет конфликта интересов.

\section{Список литературы}

[1] Brown S.B., Shillcock M. and Jones P. // Biochem. J. 1976. V. 153. P. 279.

[2] Lambert C.R., Reddi E., Spikes J.D., Rodgers M.A.J., Jori G. // Photochem. and Photobiology. 1986. V. 44. N 5. P. 595.

[3] Tanielian C., Heinrich G. // Photochem. and Photobiology. 1995. V. 61. Iss. 2. P. 131.

[4] Tanielian C., Wolff C. and Esch M. // J. Phys. Chem. 1996. V. 100(16). P. 6555.

[5] Andrade S.M., Teixeira R., Costa S.M.B., Sobral A.J.F.N. // Biophysical Chemistry. 2008. V. 133. P. 1.

[6] Sobczynski J., Tonnesen H.H., Kristensen S. // Pharmazie. 2013. V. 68. P. 100. 
[7] Lobanov A.V., Dmitrieva G.S., Sultimova N.B., Levin P.P. // Rus. J. Phys. Chem. B. 2014. V. 8. N 3. P. 272.

[8] Соловьева А.Б., Мелик-Нубаров Н.С., Аксенова Н.А., Глаголев Н.Н., Встовский Г.В., Бугрин В.С., Лузгина В.Н., Ольшевская В.А., Белкова Г.В. // ЖФХ. 2006. Т. 80. № 1. C. 137; Solov'eva A.B., Melik-Nubarov N.S., Aksenova N.A., Glagolev N.N., Vstovskii G.V., Bugrin V.S., Luzgina V.N., Ol'shevskaya V.A., Belkova G.V. // Rus. J. Phys. Chem. 2006. V. 80. N 1. P. 124.

[9] Zhientaev T.M., Melik-Nubarov N.S., Litmanovich E.A., Aksenova N.A., Glagolev N.N., Solov'eva A.B. // Polymer Science, Ser. A. 2009. V. 51. N 5. P. 502.

[10] Vilsinski B.H., Aparicio J.L., de Souza Pereira P.C., Fávaro S.L., Campanholi K.S.S., Gerola A.P., Tessaro A.L., Hioka N. and Caetano W. // Quim. Nova. 2014. V. 37. N 10. P. 1650.

[11] Дадеко А.В. // Опт. и спектр. 2016. Т. 121. № 6. С. 885; Dadeko A.V. // Opt. Spectrosc.. 2016. V. 121. № 6. P. 823.

[12] Савко М.А., Аксенова Н.А., Акишина А.К., Хасанова О.В., Глаголев Н.Н., Румянщева В.Д., Жданова К.А., Спокойный А.Л., Соловьева А.Б. // ЖФХ. 2017. Т. 91. № 11. C. 1970; Savko M.A., Aksenova N.A., Akishina A.K., Khasanova O.V., Glagolev N.N., Rumyantseva V.D., Zhdanova K.A., Spokoinyi A.L., and A.B. Solov'eva. // Rus. J. Phys. Chem. A. 2017. V. 91. N 11. P. 2260.

[13] Solovieva A.B., Kardumian V.V., Aksenova N.A., Belovolova L.V., Glushkov M.V., Bezrukov E.A., Sukhanov R.B., Kotova S.L., Timashev P.S. // Scientific Reports. 2018. V. 8. P. 8042.

[14] Муравьева Т.Д., Дадеко А.В., Киселев В.М., Крисько Т.К., Кисляков И.М., Крисько А.В., Стародубиев А.М., Багров И.В., Белоусова И.М., Пономарев Г.В. // Опт. журн. 2018. Т. 85. № 11. С. 65; Murav'eva T.D., Dadeko A.V., Kiselev V.M., Kris'ko T.K., Kislyakov I.M., Kris'ko A.V., Starodubtsev A.M., Bagrov I.V., Belousova I.M., Ponomarev G.V. // J. Optical Technology. 2018. V. 85. N 11. P. 709.

[15] Ion R.M., Grigorescu M., Scarlat F., Niculescu V.I.R., Scarlat FL., Gunaydin K. // Rom. Reports in Physics. 2001. V. 53. N 3-8. P. 281.

[16] Tonizzo A., Cerminara M., Macchi G., Meinardi F., Periasamy N., Sozzani P., Tubino R. // Synthetic Metals. 2005. V. 155. P. 291.

[17] Багров И.В., Дадеко А.В., Киселев В.М., Муравьева Т.Д., Стародубцев А.М. // Опт. и спектр. 2019. Т. 126. № 2. C. 170; Bagrov I.V., Dadeko A.V., Kiselev V.M., Murav'eva T.D., Starodubtsev A.M. // Opt. Spectrosc. 2018. V. 125. N 6. P. 911.

[18] Багров И.В., Дадеко А.В., Киселев В.М., Муравьева Т.Д., Стародубцев А.М. // Опт. и спектр. 2019. Т. 126. № 2. C. 162; Bagrov I.V., Dadeko A.V., Kiselev V.M., Murav'eva T.D., Starodubtsev A.M. // Opt. Spectrosc. 2018. V. 125. N 6. P. 903.

[19] Cai K., Xie J., Zhang D., Shi W., Yan Q., Zhao D. // J. Am. Chem. Soc. 2018. V. 140(17). P. 5764.

[20] Li X., Zhang L., Mu J. // Colloids and Surfaces A: Physicochemical and Engineering Aspects. 2007. V. 311. Iss. 1-3. P. 187.

[21] Sobczyński J., Kristensen S., Berg K. // Photochem. Photobiol. Sci. 2014. V. 13. P. 8.

[22] Shatalova O.V., Krivandin A.V., Aksenova N.A., Solov'eva A.B. // Polymer Science, Ser. A. 2008. V. 50. N 4. P. 417.
[23] Sobczyński J., Smistad G., Hegge A.B., Kristensen S. // J. Drug Development and Industrial Pharmacy. 2015. V. 41. Iss. 8. P. 1237.

[24] Горох Ю.А., Аксенова Н.А., Соловьева А.Б., Ольшевская В.А., Зайщев А.В., Лагутина М.А., Лузгина В.Н., Миронов А.Ф., Калинин В.Н. // ЖФХ. 2011. Т. 85. № 5, C. 959; Goroh Yu.A., Aksenova N.A., Solovyova A.B., Olshevskaya V.A., Zaitsev A.V., Lagutina M.A., Luzgina V.N., Mironov A.F., Kalinin V.N. // Rus. J. Phys. Chem. 2011. V. 85. N 5. P. 871.

[25] Aksenova N.A., Oles T., Sarna T., Glagolev N.N., Chernjak A.V., Volkov V.I., Kotova S.L., Melik-Nubarov N.S., Solovieva A.B. // Laser Physics. 2012. V. 22. Iss. 10. P. 1642. 